\title{
Surfactant-Free Production of Ni-Based Nanostructures
}

\author{
Yaser Bahari Mollamahaleh ${ }^{1}$, Davood Hosseini ${ }^{2}$, Mehdi Mazaheri ${ }^{3}$, Sayed Khatiboleslam Sadrnezhaad ${ }^{4^{*}}$ \\ ${ }^{1}$ Institute for Nanoscience \& Technology, Sharif University of Technology, Tehran, Iran; ${ }^{2}$ Department of Physics, University of \\ Barcelona, Barcelona, Spain; ${ }^{3}$ Swiss, Federal Institute of Technology in Lausanne (EPFL), Lausanne, Switzerland; ${ }^{4}$ Center of \\ Excellence for Advanced Materials, Department of Materials Science and Engineering, Sharif University of Technology, Tehran, \\ Iran. \\ Email: sadrnezh@sharif.edu
}

Received April 2 $2^{\text {nd }}, 2011$; revised April 18 ${ }^{\text {th }}, 2011$; accepted May $6^{\text {th }}, 2011$.

\begin{abstract}
This paper introduces a facile surfactant-free method for fabrication of different types of Ni-based nanostructures including metallic nickel nanoparticles (MNNP), nickel oxide nanoparticles (NONP) and chip-like nickel oxide nanoflakes $(C N O N F)$ by solvothermal technique at $190^{\circ} \mathrm{C}$. Nickel acetyl acetonate $\left(\mathrm{Ni}(\text { ac.ac })_{2}\right)$ was used as nickel precursor for both MNNP and CNONF and $\mathrm{NiCO}_{3} \cdot 2 \mathrm{Ni}(\mathrm{OH})_{2} \cdot n \mathrm{H}_{2} \mathrm{O}$ was utilized for NONP. Organic alcohols including 1-hexanol and benzyl alcohol were used as solvent to produce all powders. The crystallite sizes of MNNP, NONP and CNONF were determined by X-ray diffraction $(X R D)$ to be 30, 9 and $27 \mathrm{~nm}$, respectively. Electron microscopy indicated final particle sizes of $80 \mathrm{~nm}$ and $20 \mathrm{~nm}$ for MNNP and NONP, respectively and a thickness-layer less than $90 \mathrm{~nm}$ for CNONF. Brunauer-Emmett-Teller (BET) experiment determined a high surface area of $68 \mathrm{~m}^{2} / \mathrm{gr}$ for CNONF.
\end{abstract}

Keywords: Nanoparticles, Nickel, Nickel Oxide, Chip-Like Nanoflakes, Solvothermal Technique

\section{Introduction}

Powder synthesis with controlled dimension, shape and size-distribution has been a major challenge in colloid chemistry for decades. Nanoscience research has so far been mostly pertained to the development and synthesis of nanopowders and nanostructures [1]. Nanostructured particles have, in fact, engrossed many practitioners by outstanding physical and chemical properties as well as many fascinating behaviors [1,2]. Introducing a facile approach for fabrication of various morphologicallycontrolled nanopowders is of great significance to the technological advancement of the subject.

Metallic nanoparticles have attracted much attention during past two decades due to their unique properties and widespread potential applications [3]. MNNP is a distinct example which has recently engrossed practitioners by its potential applications in magnetic sensors, memory devices, conducting materials and catalysts [4]. Although techniques such as laser-ablation and evaporation-condensation have been applied to fabrication of metallic nanoparticles, high instrumental costs, complicated vacuum operation and low production rate usually associated with vacuum-based methods are still of major concerns [3].

A few solution based chemical methods has been developed to prepare metallic nanoparticles [3]. Practices such as thermal decomposition [5,6], supercritical alcohol treatment [3], thermolytic controlled reaction [4], gelatin induced reduction [7] and electroless deposition [8] have successfully been applied to produce MNNP. A simple technique to circumvent the problem of aqueous chemistry is to synthesize the organic solvents with exclusion of water. Niederberger and his coworkers [11,12] introduced a general method for synthesis of inorganic nanomaterials using organic chemistry in their published reports [1,9-12]. This method called nonaqueous or nonhydrolytic pathway has several advantages over the aqueous ways. Surfactant-free fabrication, high crystallinity of the particles, dual role of the organic solvent (as solvent and ligand), reducing metal oxide synthesis complexities and introducing size/shape controlling facilities are some examples $[1,9]$.

In nonaqueous synthesis, the organic solvent besides the ordinary effect can also cap the surface of the particles $[1,8,12]$. This effect minimizes the amount of the surfactant needed. Nonaqueous synthesis can also help to 
eliminate the calcination step of the metal oxide fabrication process which usually has particle growth effect. Surfactant-assisted methods show outstanding control over grain size by capping of the nanoparticle surfaces [13]. Surface capping provides several other advantages like low agglomeration, good dispersibility, shape control and potential to tailor surface properties of the produced nanoparticles [9]. Nanomaterial toxicity due to the surface attachments is, however, a major drawback especially in the gas sensing and catalysis practices [9].

Nickel oxide - usually considered as a model of p-type material-is a promising antiferromagnetic semiconductor with wide band gap of 3.6 - $4.0 \mathrm{eV}$ [14]. Nanocrystalline $\mathrm{NiO}$ is expected to possess improved properties when compared to micrometer-sized $\mathrm{NiO}$ particles due to quantum size, surface, volume and macroscopic quantum tunneling effects [15]. NiO nanostructures have, indeed, attracted vast number of researchers because of its chemical stability, excellent and unique electrical, optical and magnetic properties, outstanding catalysis effects and application in gas sensing, chemical sensing (particularly as a negative electrode in Li-ion batteries and fuel cells), electrochromic behavior and magnetic and electrochemical super-capacitance [14-17]. Various procedures such as thermal decomposition [18,19], microemulsion [20], precipitation $[13,15,16,21]$, electrodeposition [22, 23] sonochemistry [24] and nonaqueous [25] methods have been applied for $\mathrm{NiO}$ fabrication.

The solvothermal method is economically feasible for preparation of the monodispersed metal oxide particles of various shapes and sizes [12]. It exhibits the advantages of simplicity, high yield and straightforward particle-size control [21]. Solvent-directed processes involve the reaction of metal oxide precursor(s) with a common organic solvent and usually take place at lower temperatures $\left(50^{\circ} \mathrm{C}-250^{\circ} \mathrm{C}\right)$. Small number of reactants (precursor and solvent) makes it easily possible to study the chemical mechanisms. Solvothermal methods have exhibited great success in synthesizing the various crystalline metaloxide nanomaterials for many systems but a few published works have reported simple solvothermal method for $\mathrm{Ni}$ and $\mathrm{NiO}$ synthesis [9]. In the present work, a general surfactant-free nonaqueous solvothermal route is presented for production of MNNP and NONP nanoparticles. Method of synthesis of chip-like NiO nanoflakes having nanometric thicknesses with smooth surfaces are also presented.

\section{Experimental Procedure}

The schematic representation of the procedures used in this research is illustrated in Figure 1. Both scanning electron microscopy (SEM) and transmission electron microscopy (TEM) are used to determine the nanocristalline morphology of the produced samples.

\subsection{Synthesis of MNNP}

$\mathrm{Ni}(\mathrm{ac} . \mathrm{ac})_{2}$ nickel complex (1.0 gr) was dissolved into an organic solvent including organic alcohols listed in Table 1. The mixture was magnetically stirred until a homogenous solution was obtained. During stirring, the temperature of the solution was gradually increased up to about $70^{\circ} \mathrm{C}$. A Teflon-lined stainless steel autoclave was



Figure 1. Schematics of the procedures used in this research for production of different Ni-base nanostructures. 
Table 1. Solvents used in MNNP fabrication tests.

\begin{tabular}{cccc}
\hline Sample & $\begin{array}{c}\text { Benzyl alcohol } \\
\text { vol\% }\end{array}$ & $\begin{array}{c}\text { 1-Hexanol } \\
\text { vol\% }\end{array}$ & $\begin{array}{c}\text { Ethylene glycol } \\
\text { vol\% }\end{array}$ \\
\hline S1 & 100 & - & - \\
S2 & 20 & 80 & - \\
S3 & - & - & 100 \\
\hline
\end{tabular}

filled with the homogenous solution up to $75 \mathrm{vol} \%$ and sealed and placed in a furnace which was preheated to $190^{\circ} \mathrm{C}$. The autoclave was kept in the furnace for about $24 \mathrm{~h}$ at $190^{\circ} \mathrm{C}$. The autoclave was then pulled out of the furnace and cooled down freely in atmosphere. This step was usually accompanied with formation of a black precipitate. The black precipitate was then filtered and repeatedly rinsed (5 times) with pure ethanol. It was then dried for $24 \mathrm{~h}$ at $60^{\circ} \mathrm{C}$ in oven. These cleaning procedures were performed to remove the chemicals possibly adsorbed on the surface of precipitates to reduce the agglomeration potential.

\subsection{Synthesis of NONP}

$\mathrm{NiCO}_{3} \cdot 2 \mathrm{Ni}(\mathrm{OH})_{2} \cdot 4 \mathrm{H}_{2} \mathrm{O}(1.0 \mathrm{gr})$ was dissolved in an organic solution containing $50 \mathrm{cc}$ benzyl alcohol and $10 \mathrm{cc}$ 1-hexanol. The mixture was magnetically stirred until it became homogenous. Following the same procedure as that for MNNP, a green precipitate was deposited. The precipitate was then filtered and repeatedly rinsed with absolute ethanol (5 times) and dried for $24 \mathrm{~h}$ at $60^{\circ} \mathrm{C}$ in oven. The dried powder was finally calcined at $350^{\circ} \mathrm{C}$ for about $1 \mathrm{~h}$. The product was a black powder collected for further investigation.

\subsection{Synthesis of CNONF}

Nickel acetyl acetonate $\left(\mathrm{Ni}(\mathrm{ac} . \mathrm{ac})_{2}\right)(1.0$ gr) was dissolved in an organic solvent which included $10 \mathrm{cc}$ benzyl alcohol and $40 \mathrm{cc}$ 1-hexanol. Magnetic stirring of the mixture was continued until a homogenous solution was formed. Hydrogen peroxide was added according to the same procedure as specified for NONP until CNONF was precipitated.

\section{Results and Discussion}

The XRD pattern of the black sediment precipitated from S1 and S2 solutions (Table 1) are illustrated in Figure 2. All diffraction peaks are indexed as cubic Ni $(a=3.523$ A) according to the standard JCPDS card No. 04-0580. From Figure 2, one can infer the high crystallinity of MNNP which is consistent with the previous findings [9,11]. The crystallite sizes obtained from the XRD patterns are determined to be $25 \mathrm{~nm}$ and $19 \mathrm{~nm}$ for $\mathrm{S} 1$ and S2 solutions, respectively. The average crystallite size of

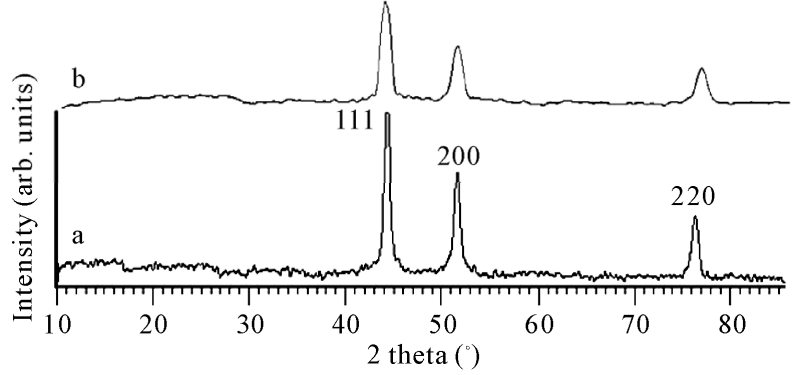

Figure 2. XRD pattern of the Ni nanoparticles in: (a) S1 and (b) $\mathrm{S} 2$.

the powders is determinable by applying the Scherrer equation:

$$
d=k \lambda /(\beta \cos \theta)
$$

where $d$ is the size of the crystallites, $k$ is a constant depending on the crystalline shape, $\lambda$ is the wavelength, $\beta$ is the half-maximum full-width of the intensity peak and $\theta$ is the diffraction angle of the sample.

Black color of the solutions confirmed the presence of metallic nickel in all experiments. SEM images of the MNNP products are depicted in Figure 3. Benzyl alcohol results in the spherical morphology of the MNNP sediment. The powder has uniformly distributed particles of $120 \pm 10 \mathrm{~nm}$ size with low agglomeration. Figure 3(a) indicates MNNP particle size-control due to the benzyl alcohol capping effect. Benzyl alcohol seems, therefore, a good solvent of mild surfactant nature. In comparison with S1, growth of the particles is reduced in S2 (Figure 3(b)). Majority of the particles in Figure 3(b) have a size of about $90 \pm 5 \mathrm{~nm}$. It seems, therefore, that by adding more hexanol to the solution, size control of the MNNP sample can be improved and the particle size can dramatically reduce. These can be described as follow: alcohol molecules can surround $\mathrm{Ni}(\mathrm{ac} . \mathrm{ac})_{2}$ in the solution. When the temperature increases above $180^{\circ} \mathrm{C}-190^{\circ} \mathrm{C}$, $\mathrm{Ni}(\mathrm{ac} . \mathrm{ac})_{2}$ breaks into its components $(\mathrm{Ni}$ and organic ligand) and $\mathrm{Ni}$ nucleation causes mixture change into black color. The organic solvent acts, on the other hand, as a surfactant and controls growth of the $\mathrm{Ni}$ nucleates while preventing them from agglomeration. Organic solvent and organic chain of the broken $\mathrm{Ni}(\mathrm{ac} . \mathrm{ac})_{2}$ both act as barriers for diffusion of the particles. This mechanism is similar to the steric stabilization. Despite the spatial conformation of hexanol, when both hexanol and benzyl alcohol are applied to the solution, capping occurs more effectively than sole presence of benzyl alcohol.

It is interesting to note that the utilized synthesis method is not restricted to a specific organic solvent. While the MNNP particle size is crucially affected by the length of the organic solvent. The mean particle size of S3 (Figure 3(c)) produced in ethylene glycol is, for ex- 


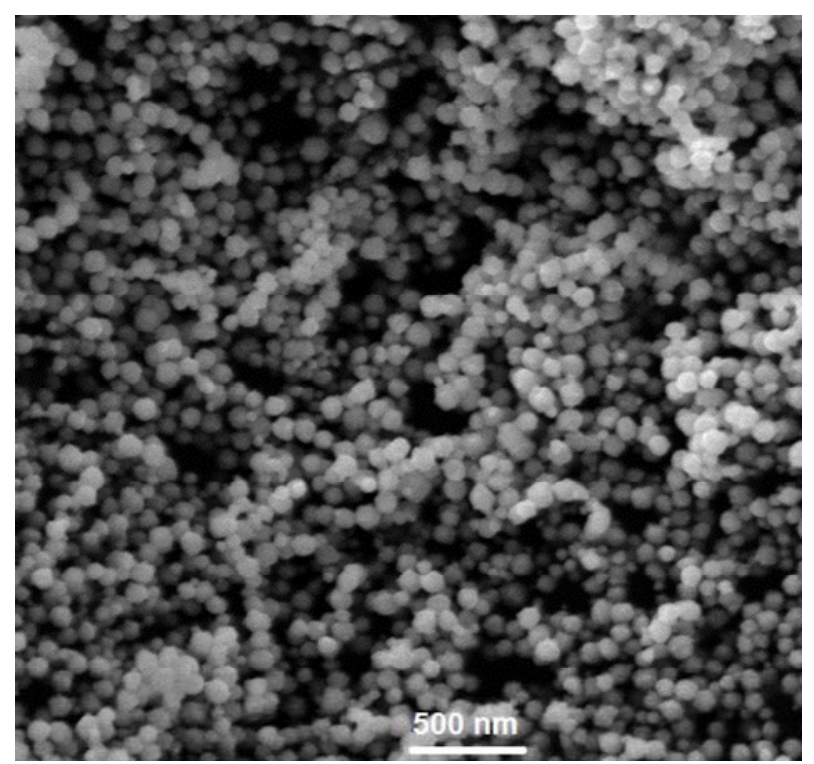

(a)



(c)



(b)

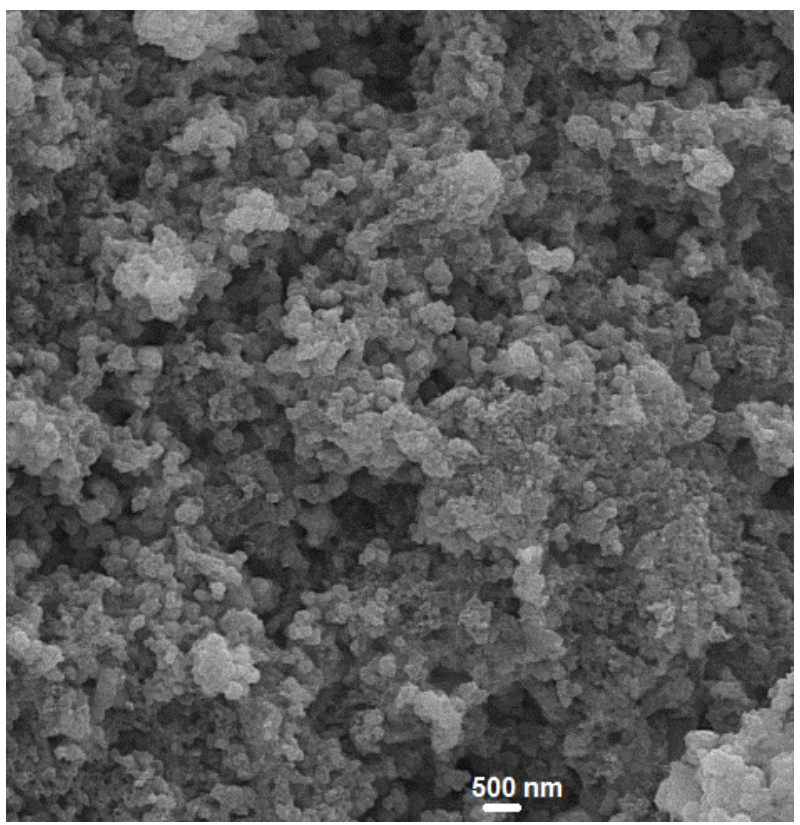

(d)

Figure 3. SEM images of: (a) S1, (b) S2, (c) S3 and (d) NONP sediments. All S1-S3 samples indicate spherical morphology. S2 has the smallest particle size.

ample, more than $200 \mathrm{~nm}$. This can be related to the short length of the ethylene glycol chain. Song et al. [17] have reported that ethylene glycol can serve as a ligand reacting with metal ions to form linear coordination complexes. They have clearly observed that this cannot lead to a nanoscale powder. It is worth mentioning that all the samples have had a spherical morphology. Ni particles have, in fact, had a tendency to form spherical shapes in the organic solvent to minimize their surface free energy.
In spite of the long aging time, Ostwald ripening would have occurred leading to a nearly uniform particle size distribution [26]. In the Ostwald ripening mechanism, large particles grow at the expense of the smaller particles which are more soluble [26]. Niderbeger has reported on the use of benzyl alcohol as a solvent [9]. This has resulted in formation of metal oxide nanoparticles [9]. Benzyl alcohol here has followed a different way which has resulted in the formation of the metallic nanoparticles. 
It has been proposed, additionally, that the use a solvent with a longer chain can effectively lower the size of the particles.

Present work shows a facile single-step nonaqueous route for synthesis of the MNNP particles. With previous synthesis methods, if $\mathrm{Ni}(\mathrm{ac} . \mathrm{ac})_{2}$ is replaced with

$\mathrm{NiCO}_{3} \cdot 2 \mathrm{Ni}(\mathrm{OH})_{2} \cdot 4 \mathrm{H}_{2} \mathrm{O}$, a green precipitate is obtained. The XRD pattern shows no obvious diffraction peak indicating this precipitate (Figure 4(a)). The FTIR spectrum of the green precipitate is shown in Figure 5. The broad absorption band centered at $3400 \mathrm{~cm}^{-1}$ is attributed to the $\mathrm{O}-\mathrm{H}$ band stretching vibrations. The band at 1615 $\mathrm{cm}^{-1}$ attributes to $(\mathrm{H}-\mathrm{O}-\mathrm{H})$ bending mode. Wave numbers of $1457 \mathrm{~cm}^{-1}$ and $1383 \mathrm{~cm}^{-1}$ can be assigned to bending vibrations of the $\mathrm{CH}_{3}$ group, $\delta\left(\mathrm{CH}_{3}\right)$. The band at $1383 \mathrm{~cm}^{-1}$ is also primarily related to the banding vibration of the ionic $\mathrm{CO}_{3}^{2-}$. The strong band at $420 \mathrm{~cm}^{-1}$ corresponds to the stretching mode of the $\mathrm{NiO}$ particles.

Figure 6 shows the TG-DTA decomposition curve of the green precipitate. From room temperature to $260^{\circ} \mathrm{C}$, the weight loss can be caused by desorption of water from the surface of the green precipitate. The major weight loss happens from $260^{\circ} \mathrm{C}$ to $300^{\circ} \mathrm{C}$ which accompanies a sharp DTA peak. The weight loss value attributed to this transformation is close to the thermal decomposition or the dehydration of $\mathrm{Ni}(\mathrm{OH})_{2}$ to form $\mathrm{NiO}$ particles. Based on characterization investigations, one can conclude that the green precipitate is $\mathrm{Ni}(\mathrm{OH})_{2}$ with low crystallinity. According to JCPDS Nu. 44-1159, all XRD peaks of the calcined product correspond to the $\mathrm{NiO}$ structure (Figure 4(b)). Applying the Debye-Scher- rer formula, the crystallite size of the as-prepared $\mathrm{NiO}$ is calculated to be $9 \mathrm{~nm}$.

Figure 3(d) shows highly agglomerated NONP particles. Substitution of nickel-organic substance with an inorganic nickel compound has resulted in a totally different effect on conformation of the molecules rather

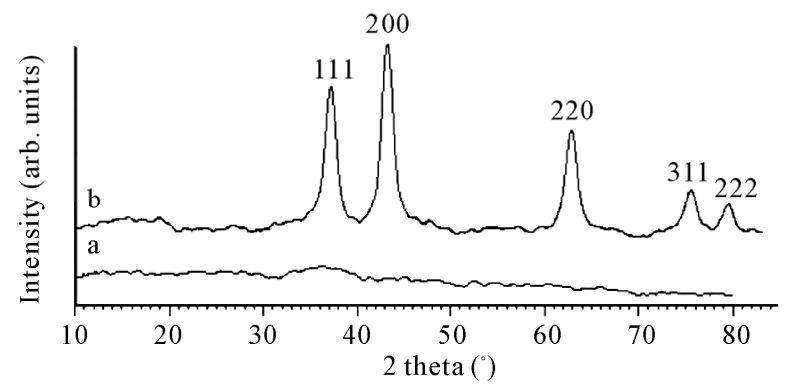

Figure 4. XRD pattern of the green NONP precipitate: (a) before calcination and (b) after calcination at $350^{\circ} \mathrm{C}$.

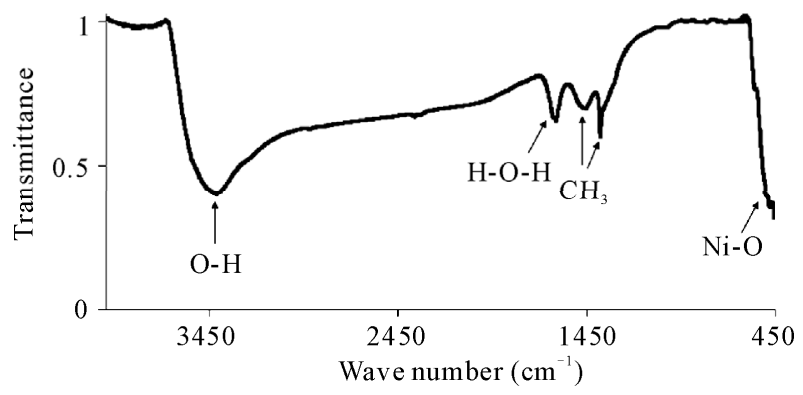

Figure 5. FTIR spectrum of the green NONP precipitate before calcination.

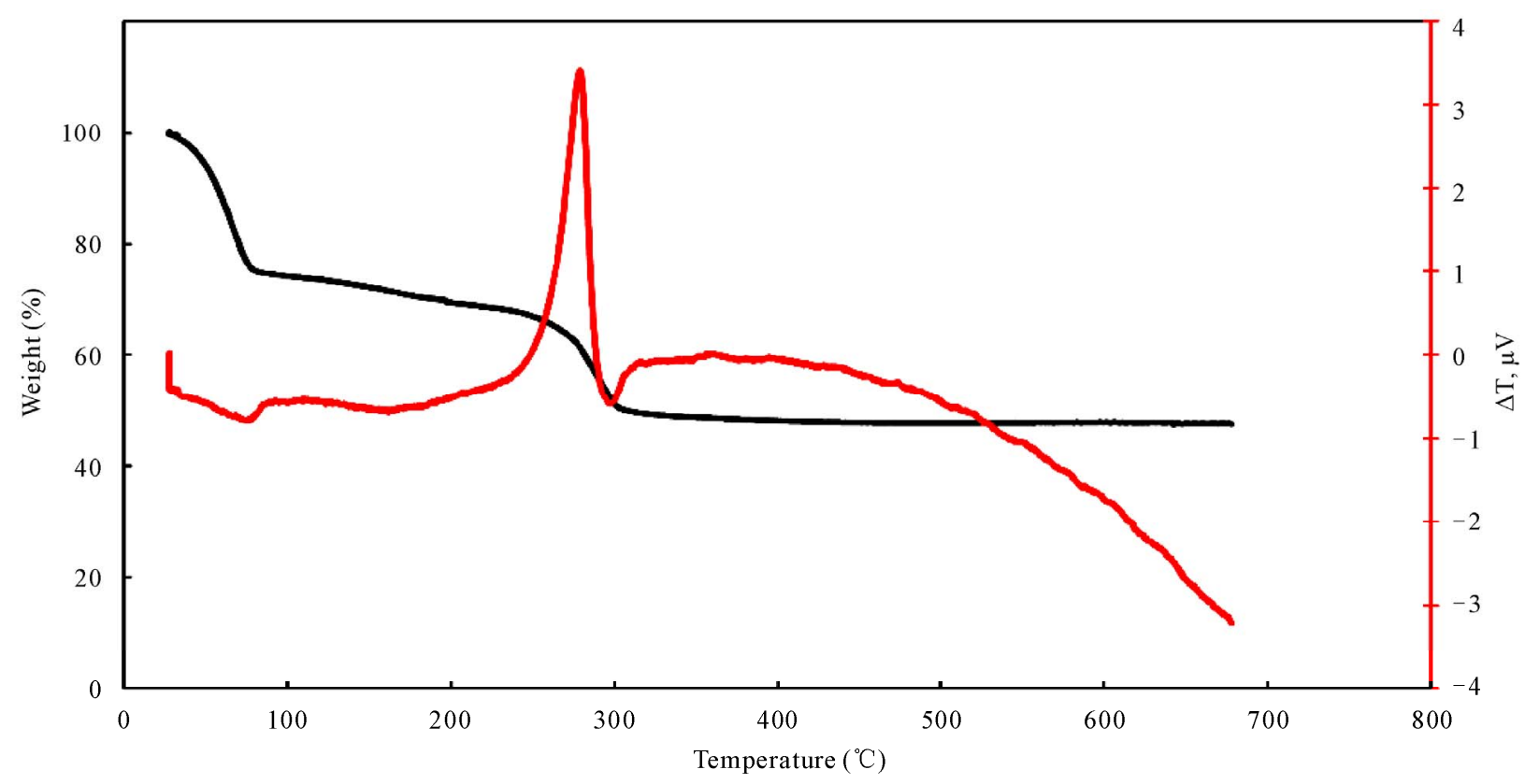

Figure 6. TG-DTA curve of the green NONP precipitate. 
than their pathway and composition. Not only the solvent is, hence, important in determining the property of the final product, the initial precursor composition is also

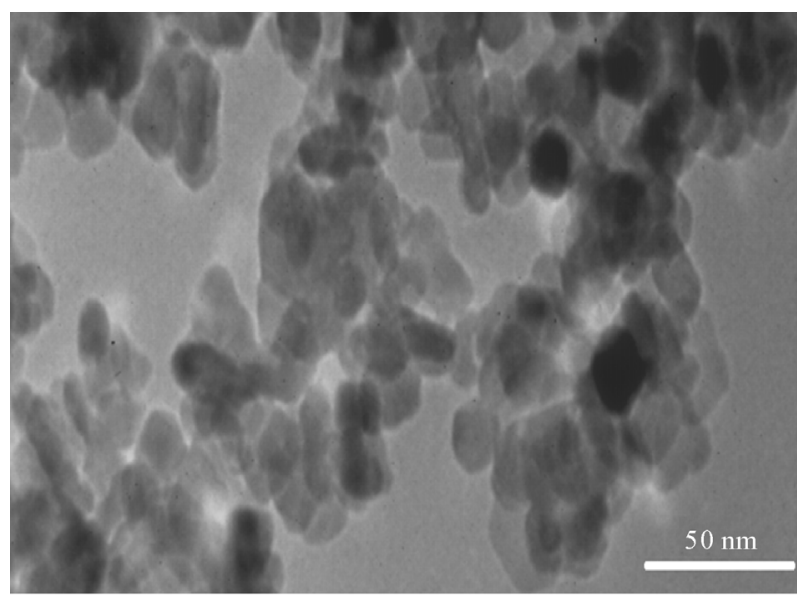

(a) significant. A totally different chemistry is, hence, dominant for each product. The nonaqueous synthesis is a one-step process for preparation of the MNNP; while the

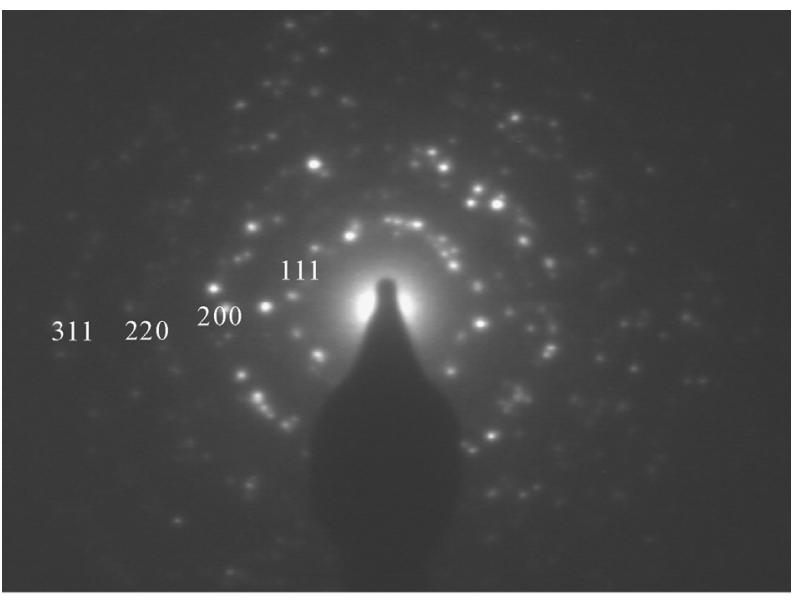

(b)

Figure 7. TEM NONP: (a) nanostructural image and (b) diffraction pattern.

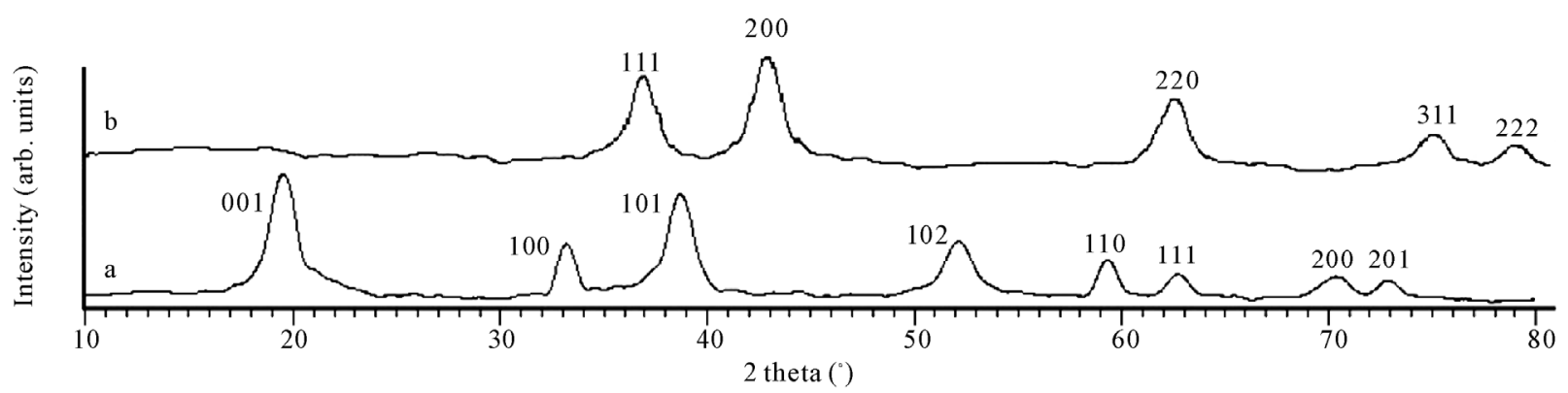

Figure 8. XRD pattern of CNONF green precipitate: (a) before calcination and (b) after calcination at $350^{\circ} \mathrm{C}$.

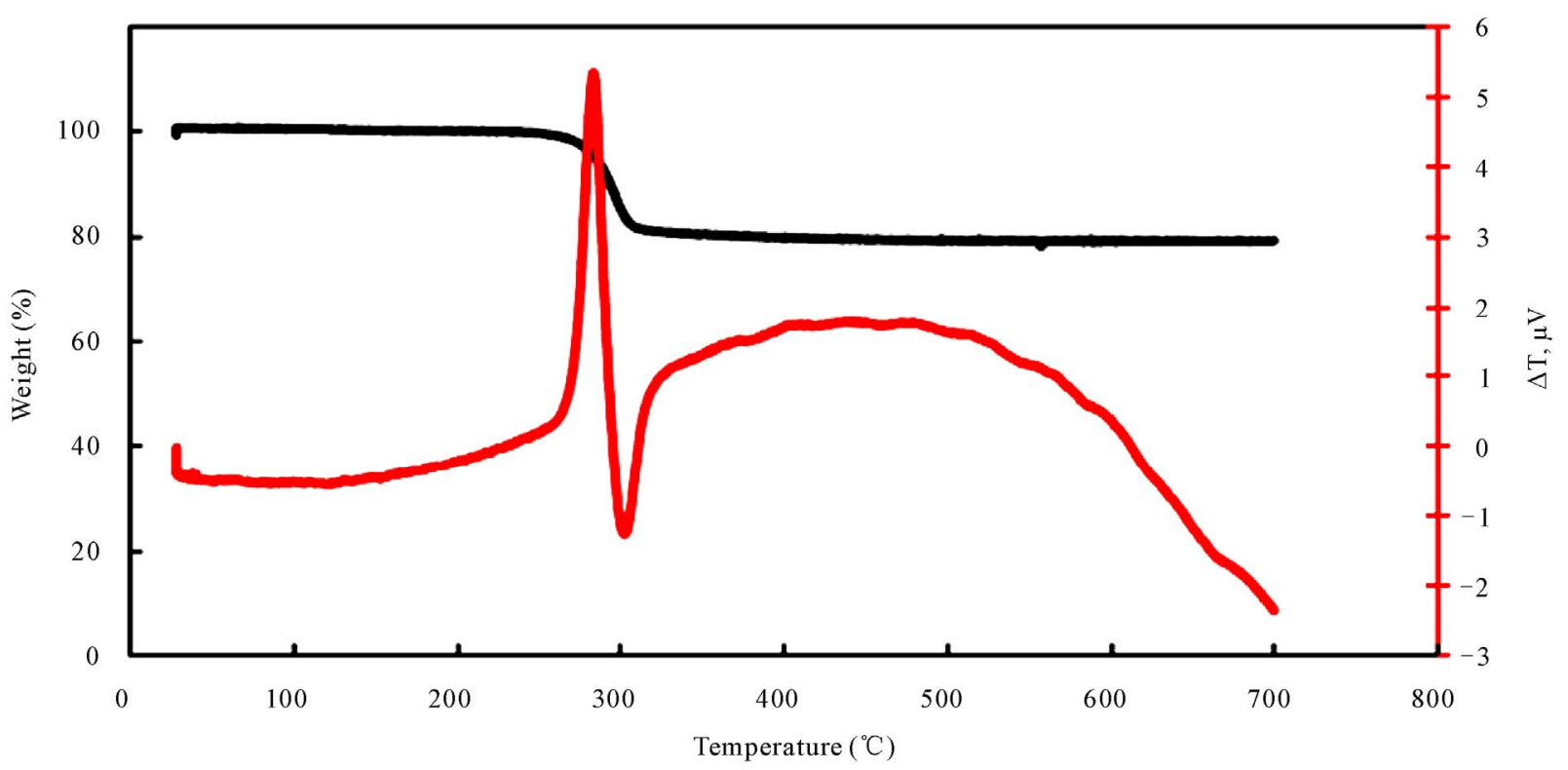

Figure 9. TG-DTA curve of CNONF green precipitate. 
two-step $\mathrm{NiO}$ preparation is based on the organic-inorganic reaction which accompanies thermal decomposition. Figure 7 illustrates the TEM image of the NONP sample. The size of the relatively low agglomerated particles is estimated about $20 \mathrm{~nm}$.

BET analysis showed the surface area of the NONP particles to be $33 \mathrm{~m}^{2} / \mathrm{gr}$. Assuming that the particles are same-sized spheres with smooth surfaces, the surface area can be related to the average equivalent particle size by $d=6000 /(\rho \cdot S)$ (in nm), where $d$ is the average diameter of the spherical particles in nanometer; $\rho$ is the theoretical density of $\mathrm{NiO}\left(6.67 \mathrm{~g} / \mathrm{cm}^{3}\right)$ and $S$ represents the measured surface area of the powder in $\mathrm{m}^{2} / \mathrm{g}$. The specific surface area is determined to be $33 \mathrm{~m}^{2} / \mathrm{g}$; while the equivalent average particle size evaluated by TEM is $27 \mathrm{~nm}$. The particle sizes obtained from BET and TEM are, thus, in good agreement.

The third product is CNONF. The initial procedure for its production is similar to $\mathrm{S} 1$ except that $10 \mathrm{cc}$ hydrogen peroxide is added to the solution which results in a green precipitate like NONP; but different in its appearance for being agglomerated. The XRD pattern of the green precipitate is shown in Figure 8(a) indicating $\mathrm{Ni}(\mathrm{OH})_{2}(03-$ 0177) with crystallite size of $27 \mathrm{~nm}$ determined by De-

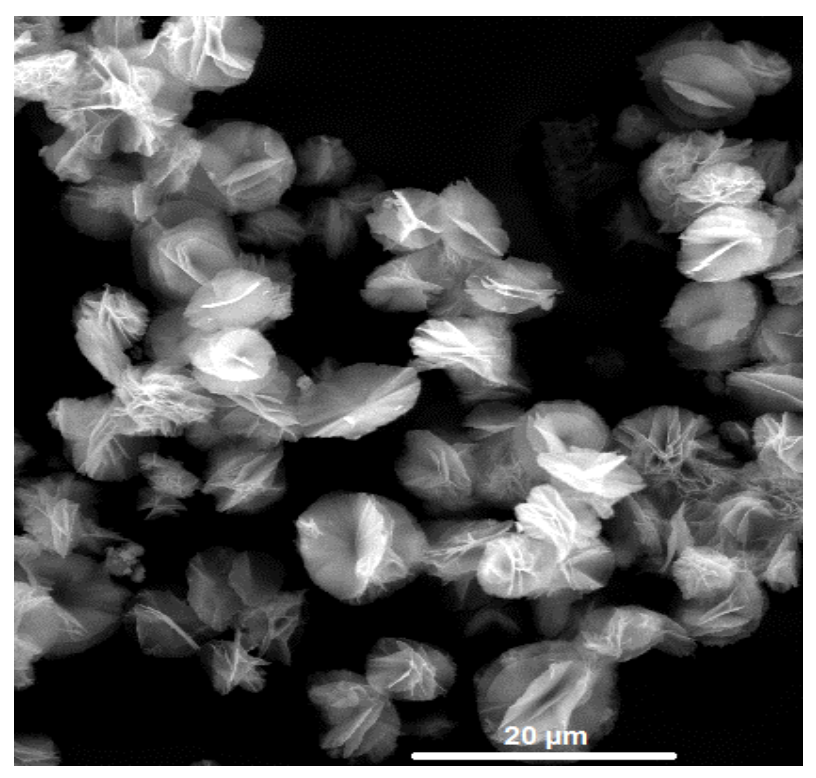

(a)

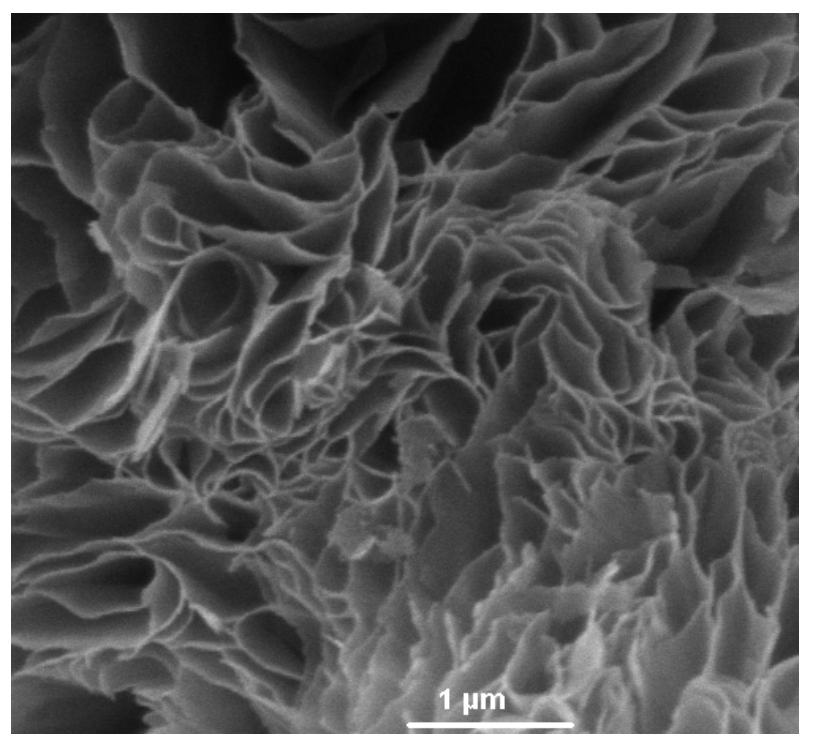

(c)

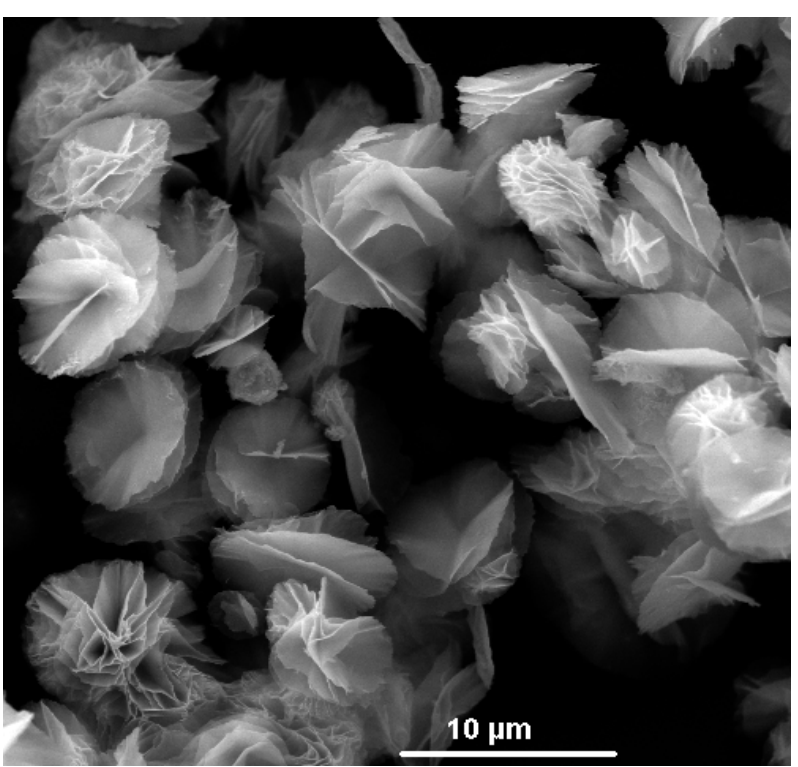

(b)

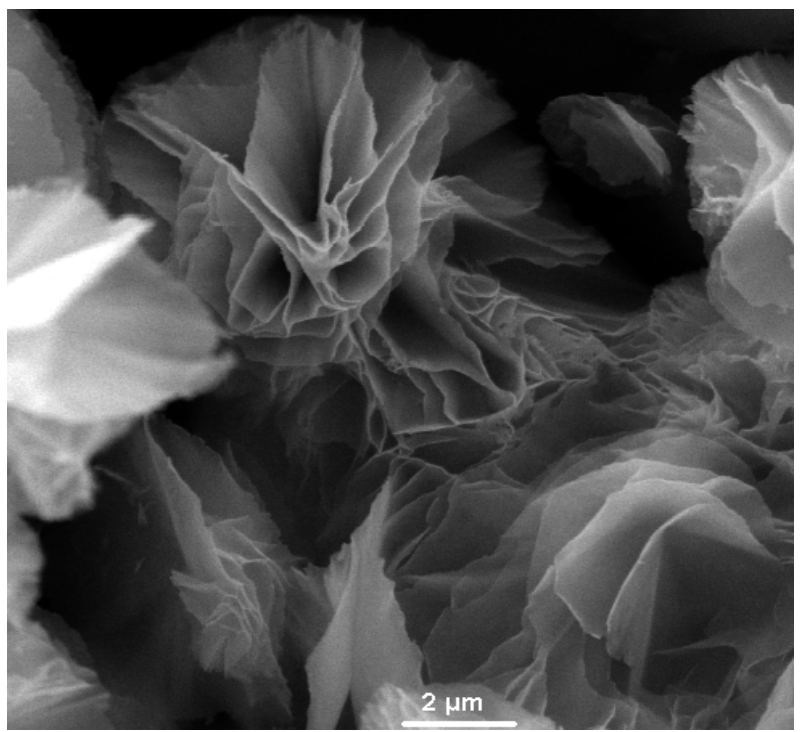

(d)

Figure 10. SEM image morphologies of CNONF at magnification: (a) 2 kx, (b) 4 kx, (c) 10 kx and (d) 30 kx. 


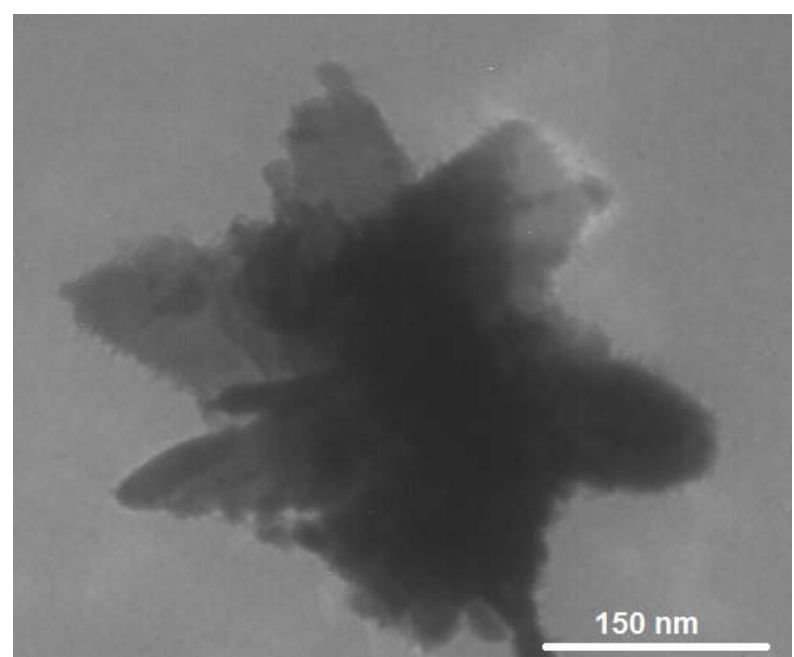

(a)



(b)

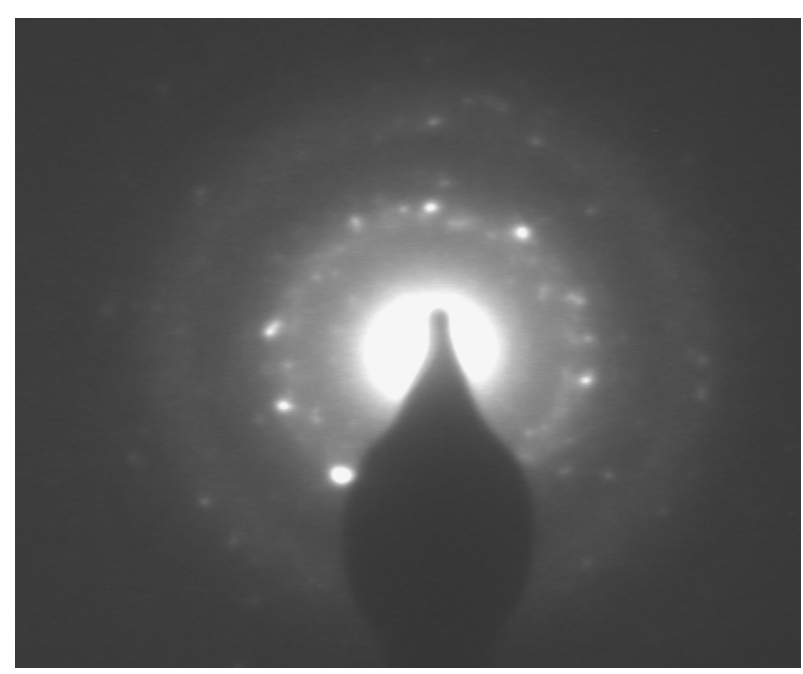

(c)

Figure 11. TEM CNONF: (a and b) images and (c) diffraction pattern.
bye-Scherrer correlation. In the TG-DTA graph (Figure 9), one can observe the simple decomposition of $\mathrm{Ni}(\mathrm{OH})_{2}$ to $\mathrm{NiO}$ below $300^{\circ} \mathrm{C}$ without any other pertinent weight loss effect. Diffraction peaks of Figure 8(b) belong to $\mathrm{NiO}$ structure with crystallite size of $30 \mathrm{~nm}$ according to JCPDS Nu. 44-1159. Morphology of the as-produced $\mathrm{NiO}$ nanostructure is illustrated in Figures $\mathbf{1 0}$ and $\mathbf{1 1 .}$ SEM images of platelet chip-like structures belonging to $\mathrm{NiO}$ (Figure 10) is confirmed by TEM images shown in Figure 11(a) having less than $90 \mathrm{~nm}$ thickness (Figure 11(b)) and some crystallinity presence (Figure 11(c)). BET analysis showed surface area of $68 \mathrm{~m}^{2} / \mathrm{gr}$ for the as-produced CNONF which was about two times that of NONP. Due to its high surface area, the prepared structure seemed useful for catalytic application.

\section{Conclusions}

Different chemistries are applied to similar solvothermal procedure to achieve three nickel-based nanostructures: MNNP, NONP and CNONF. With the aid of nonaqueous chemistry, a spherical uniform morphology is obtained for metallic nickel. The starting solvent has crucial role on the particle size of the powder. Based on the SEM results, the particle sizes of the sediments precipitated from S1 and S3 are 110, 90 and $300 \mathrm{~nm}$. A long chain organic compound mixed with (or even without) benzyl alcohol seems to be able to effectively reduce these particle sizes. By application of the aqueous-organic chemistry into the system, the $\mathrm{NiO}$ nanostructure can be obtained as small as $20 \mathrm{~nm}$. Using an oxidant such as $\mathrm{H}_{2} \mathrm{O}_{2}$, chip-like nickel oxide nanoflakes less than $90 \mathrm{~nm}$ in thickness and having an interesting morphology is obtained. BET results show highly active surface areas of $68 \mathrm{~m}^{2} / \mathrm{g}$ for CNONF and 33 $\mathrm{m}^{2} / \mathrm{g}$ for NONP synthesized powders.

\section{Acknowledgements}

The authors wish to thank the financial support of the Iran National Science Foundation.

\section{REFERENCES}

[1] I. Djerdj, D. Arcon, Z. Jaglicic and M. Niederberger, "Nonaqueous Synthesis of Metal Oxide Nanoparticles: Short Review and Doped Titanium Dioxide as Case Study for the Preparation of Transition Metal-Doped Oxide Nanoparticles," Journal of Solid State Chemistry, Vol. 181, No. 7, July 2008, pp. 1571-1581.

doi:10.1016/j.jssc.2008.04.016

[2] L. Zhou, J. Xu, X. Li and F. Wang, "Metal Oxide Nanoparticles from Inorganic Sources via a Simple and General Method," Materials Chemistry and Physics, Vol. 97, No. 1, May 2006, pp. 137-142. doi:10.1016/j.matchemphys.2005.07.062

[3] J. Kim, D. Kim, B. Veriansyah, J. W. Kang and J. D. Kim, 
"Metal Nanoparticle Synthesis Using Supercritical Alcohol," Materials Letters, Vol. 63, No. 21, August 2009, pp. 1880-1882. doi:10.1016/j.matlet.2009.05.066

[4] S. Mourdikoudis, K. Simeonidis, A. Vilalta-Clemente, F. Tunab, I. Tsiaoussis, M. Angelakeris, et al., "Controlling the Crystal Structure of Ni Nanoparticles by the Use of Alkylamines," The Journal of Magnetism and Magnetic Materials, Vol. 321, No. 18, September 2009, pp. 27232728. doi:10.1016/j.jmmm.2009.03.076

[5] J. Park, E. Kang, S. U. Son, H. M. Park, M. K. Lee, J. Kim, et al., "Monodisperse Nanoparticles of Ni and NiO: Synthesis, Characterization, Self-Assembled Superlattices, and Catalytic Applications in the Suzuki Coupling Reaction," Advanced Material, Vol. 17, No. 4, 2005, pp. 429434. doi:10.1002/adma.200400611

[6] S. G. Kim, Y. Terashi, A. Purwanto and K. Okuyam, "Synthesis and Film Deposition of Ni Nanoparticles for Base Metal Electrode Applications," Colloids Surfaces A, Vol. 337, No. 1-3, April 2009, pp. 96-101. doi:10.1016/j.colsurfa.2008.12.022

[7] Y. Hattori and E. Matijevic, "Gelatin Induced Reduction of Uniform Nano-Platelets of $\mathrm{Ni}(\mathrm{OH})_{2}$ to $\mathrm{Ni}$ Metal," Journal of Colloid and Interface Science, Vol. 335, No. 1, July 2009, pp. 50-53. doi:10.1016/j.jcis.2009.03.046

[8] H. Bi, K. C. Kou, K. Ostrikov, L. K. Yan and Z. C. Wang, "Microstructure and Electromagnetic Characteristics of $\mathrm{Ni}$ Nanoparticle Film Coated Carbon Microcoils," The Journal of Alloys and Compounds, Vol. 478, No. 1-2, June 2009, pp. 796-800. doi:10.1016/j.jallcom.2008.12.053

[9] N. Pinna and M. Niederberger, "Surfactant-Free Nonaqueous Synthesis of Metal Oxide Nanostructures," Angewandte Chemie International Edition, Vol. 47, No. 29, July 2008, pp. 5292-5304. doi:10.1002/anie.200704541

[10] G. Garnweitner and M. Niederberger, "Organic Chemistry in Inorganic Nanomaterials Synthesis," Journal of Material Chemistry, Vol. 18, No. 11, 2008, pp. 1171-1182. doi: $10.1039 / \mathrm{b} 713775 \mathrm{c}$

[11] M. Niederberger and G. Garnweitner, "Organic Reaction Pathways in the Nonaqueous Synthesis of Metal Oxide Nanoparticles," Chemistry: A European Journal, Vol. 12, No. 28, September2006, pp. 7282-7302. doi:10.1002/chem.200600313

[12] M. Niederberger, "Nonaqueous Sol-Gel Routes to Metal Oxide Nanoparticles," Accounts of Chemical Research, Vol. 40, No. 9, 2007, pp. 793-800. doi:10.1021/ar600035e

[13] Y. Bahari Mollamahale, S. K. Sadrnezhaad and D. Hosseini, "NiO Nanoparticles Synthesis by Chemical Precipitation and Effect of Applied Surfactant on Distribution of Particle Size," Nanomater, 2008, 4 Pages. doi: $10.1155 / 2008 / 470595$

[14] B. Varghese, M. V. Reddy, Z. Yanwu, C. S. Lit, T. C. Hoong, G. V. Subba Rao, B. V. R. Chowdari, A. T. S. Wee, C. T. Lim and C. H. Sow, "Fabrication of NiO Nanowall Electrodes for High Performance Lithium Ion Battery," Chemistry of Material, Vol. 20, No. 10, May 2008, pp. 3360-3367. doi:10.1021/cm703512k

[15] J. Li, R. Yan, B. Xiao, D. T. Liang and D. H. Lee, "Prep- aration of Nano-NiO Particles and Evaluation of Their Catalytic Activity in Pyrolyzing Biomass Components," Energy Fuels, Vol. 22, No. 1, 2008, pp. 16-23. doi:10.1021/ef700283j

[16] M. A. Shah, "A Versatile Route for the Synthesis of Nickel Oxide Nanostructures without Organics at Low Temperature," Nanoscale Research Letters, Vol. 3, 2008, pp. 255-259. doi:10.1007/s11671-008-9147-Z

[17] X. Song and L. Gao, "Facile Synthesis and Hierarchical Assembly of Hollow Nickel Oxide Architectures Bearing Enhanced Photocatalytic Properties," The Journal of Physical Chemistry C, Vol. 112, No. 39, 2008, pp. 1529915305. doi:10.1021/jp804921g

[18] X. Li, X. Zhang, Z. Li and Y. Qian, "Synthesis and Characteristics of NiO Nanoparticles by Thermal Decomposition of Nickel Dimethylglyoximate Rods," Solid State Communications, Vol. 137, No. 11, 2006, pp. 581-584. doi:10.1016/j.ssc.2006.01.031

[19] X. Wang, J. Song, L. Gao, J. Jin, H. Zheng and Z. Zhang, "Optical and Electrochemical Properties of Nanosized $\mathrm{NiO}$ via Thermal Decomposition of Nickel Oxalate Nanofibres," Nanotechnology, Vol. 16, No. 1, 2005, pp. 3739. doi:10.1088/0957-4484/16/1/009

[20] P. Palanisamy and A. M. Raichur, "Synthesis of Spherical $\mathrm{NiO}$ Nanoparticles through a Novel Biosurfactant Mediated Emulsion Technique," Materials Science and Engineering: C, Vol. 29, No. 1, January 2009, pp. 199-204. doi:10.1016/i.msec.2008.06.008

[21] C. Li, Y. Liu, L. Li, Z. Du, S. Xu, M. Zhang, X. Yin and T. Wang, "A Novel Amperometric Biosensor Based on NiO Hollow Nanospheres for Biosensing Glucose," Talanta, Vol. 77, No. 1, October 2008, pp. 455-459. doi:10.1016/i.talanta.2008.06.048

[22] A. B. Moghaddam, M. R. Ganjali, A. A. Saboury, A. A. Moosavi-Movahedi and P. Norouzi, "Electrodeposition of Nickel Oxide Nanoparticles on Glassy Carbon Surfaces: Application to the Direct Electron Transfer of Tyrosinase," Journal of Applied Electrochemistry, Vol. 38, No. 9, 2008, pp. 1233-1239. doi:10.1007/s10800-008-9541-3

[23] A. Salimi, E. Sharifi, A. Noorbakhsh and S. Soltanian, "Immobilization of Glucose Oxidase on Electrodeposited Nickel Oxide Nanoparticles: Direct Electron Transfer and Electrocatalytic Activity," Biosens and Bioelectron, Vol. 22, No. 12, June 2007, pp. 3146-3153. doi:10.1016/j.bios.2007.02.002

[24] A. Aslani, A. Bazmandegan-Shamili and K. Kaviani, "Sonochemical Synthesis, Characterization and Optical Analysis of Some Metal Oxide Nanoparticles (MO-NP; $\mathrm{M}=\mathrm{Ni}, \mathrm{Zn}$ and Mn)," Physica B, Vol. 405, No. 18, 2008, pp. 3972-3976. doi:10.1016/j.physb.2010.06.041

[25] R. N. Jana, Y. Chen and X. Peng, "Size- and Shape-Controlled Magnetic (Cr, Mn, Fe, Co, Ni) Oxide Nanocrystals via a Simple and General Approach," Chemistry of materials, Vol. 16, No. 20, 2004, pp. 3931-3935. doi: $10.1021 / \mathrm{cm} 049221 \mathrm{k}$

[26] G. Cao, "Nanostructures and Nanomaterials," Imperial College, London, 2003. 